\title{
TRADUÇÃO E ADAPTAÇÃO LINGUÍSTICA E CULTURAL PARA A LÍNGUA PORTUGUESA DO “A QUESTIONNAIRE FOR STUDENT TEACHERS"
}

Tiago Sousa, Universidade do Porto - UP, Porto - Portugal

Mariana Cunha, Universidade do Porto - UP, Porto - Portugal

Paula Batista, Universidade do Porto - UP, Porto - Portugal

\section{RESUMO}

O presente estudo representa o primeiro passo da tradução e adaptação linguística e cultural, para a língua portuguesa, do questionário desenvolvido originalmente por Gilat, Kupferberg e Sagee ${ }^{11}$ e adaptado por Ezer, Gilat e Sagee, ${ }^{12}$ que visa aceder às perceções do estudante-estagiário sobre a formação e a profissão. Para o processo foram seguidos os princípios definidos por Geisinger ${ }^{15^{3}}$ de equivalência funcional, bem como a tradução literal, desembocando numa constante avaliação das equivalências concetuais linguísticas. Para dar resposta à aferição processo de equivalências, seguiu-se a proposta metodológica de Vallerand ${ }^{18}$ de sete etapas, sendo que este estudo se reporta às quatro primeiras: (i) construção de uma versão preliminar; (ii) avaliação e modificação da versão preliminar; (iii) avaliação da clareza das perguntas por membros da população através de um pré-teste; (iv) avaliação da validade do conteúdo do questionário. O processo de adaptação do instrumento foi alcançado com sucesso, pelo que, para que este instrumento possa ser utilizado no contexto da língua portuguesa, dever-se-á dar continuidade ao processo, procedendo-se à avaliação das equivalências psicométricas (fiabilidade e validade funcional).

Palavras-Chave: Questionário; Tradução e adaptação linguística e cultural; Percepções; Estudante-Estagiário, Formação professores.

\section{TRANSLATION AND CULTURAL-LINGUISTICS ADAPTATION TO PORTUGUESE: "A QUESTIONNAIRE FOR STUDENT TEACHERS"}

\begin{abstract}
This study represents the first step of a linguistic and cultural translation and adaptation of a questionnaire developed by Gilat, Kupferberg and Sagee, ${ }^{11}$ adapted by Ezer, Gilat and Sagee ${ }^{12}$ to Portuguese. This questionnaire aims to access the pre-service teachers' perceptions on training and profession. In the translation process we followed the principles of functional equivalence defined by Geisinger, ${ }^{15}$ which comprises going beyond literal translation, i.e. a constant review of language and conceptual equivalence. To achieve that goal, we followed the seven steps of Vallerand's ${ }^{18}$ methodological proposal. This study reports the four leading steps: i) build a draft; ii) draft's review and modification; iii) assessment of the clarity questions by members of the public throughout a pretest; iv) assessing the content validity of the questionnaire. Conexões: revista da Faculdade de Educação Física da UNICAMP, Campinas, v. 13, n. 1, p. 20-35, jan./mar. 2015. ISSN: 1983-9030
\end{abstract}


The process of adapting the instrument was successfully achieved. It is, therefore, important in future studies to assess the psychometric equivalence (functional reliability and validity), so that this instrument can be used in the context of the Portuguese language.

Key-Words: Questionnaire; Linguistic-cultural translation and adaptation; Perceptions; Pre-service teachers; Teacher education.

\title{
TRADUCCIÓN Y ADAPTACIÓN LINGÜÍSTICA Y CULTURAL PARA EL IDIOMA PORTUGUÉS: “A QUESTIONNAIRE FOR STUDENT TEACHERS"
}

\begin{abstract}
RESUMEN
Este estudio representa el primer paso de la traducción y adaptación lingüística y cultural para portugués del cuestionario desarrollado por Gilat Kupferberg y Sagee ${ }^{11}$, adaptado de Ezer, Gilat y Sagee ${ }^{12}$. Este instrumento busca acceder a las percepciones del estudiante acerca de las prácticas en la formación y la profesión. Para el proceso se han seguido los principios definidos por Geisinger ${ }^{18}$ de equivalencia funcional y traducción literal, que termina en una revisión del lenguaje de equivalencia conceptual. Para dar respuesta a las equivalencias del proceso de verificación se hay seguido la propuesta metodológica de Vallerand ${ }^{18}$ compuesta por siete pasos. En este estudio se trata apenas las primeras cuatro etapas: (i) construcción de una versión preliminar, (ii) revisión y modificación de la versión preliminar, (iii) evaluación de la clareza de las cuestiones por miembros de la populación a través de un pre-test, (iv) evaluación de la validad del contenido del cuestionario. El proceso de adaptación del instrumento se logró con éxito, pero para que este instrumento se puede utilizar en el contexto de la lengua portuguesa, se deberá continuar con el proceso haciendo la evaluación de la equivalencia psicométrica (fiabilidad y validad funcional).
\end{abstract}

Palabras-Clave: Cuestionario, Traducción y adaptación lingüística y cultural; Percepciones; Estudiante en prácticas, Formación de profesores. 


\section{INTRODUÇÃO}

Os programas de formação de professores são referenciados na literatura como elementos centrais aos processos de construção da identidade profissional do candidato a professor. ${ }^{1-5}$

Todavia, no decurso das últimas décadas, os estes programas têm sido alvo de várias alterações, tanto na sua conceção, como na operacionalização. Em Portugal, a alteração mais recente coincide com a implementação do processo de Bolonha ${ }^{1}$, que aportou transformações substanciais no paradigma formativo, isto é, deixou de se centrar na aquisição de conhecimentos, para passar a centrar-se na aquisição de competências.

Esta renovada configuração formativa, imputou novos desafios, papéis e responsabilidades às faculdades e docentes, bem como uma consequente alteração dos programas curriculares, resultando num novo modelo de educação em geral e prática docente em particular. Paralelamente, as alterações legislativas em Portugal, de acordo com o Ministério da Educação ${ }^{2}$, configuraram uma nova forma de habilitação profissional para a docência, acompanhada pela definição de perfis desempenho da atividade do professor renovados. ${ }^{6}$

Com as alterações produzidas pela referida lei de 2007, para se aceder à carreira docente passou a ser necessário o grau de mestre na área de lecionação específica, obtido em sede de curso de $2^{\circ}$ ciclo de estudos. Deste modo, o candidato a professor, após realizar o $1^{\circ}$ ciclo de formação mais geral no âmbito das ciências do desporto (no caso de professor de Educação Física), prossegue os estudos no $2^{\circ}$ ciclo em ensino da Educação

\footnotetext{
${ }^{1}$ O processo de Bolonha resultou da convenção dos 29 ministros da educação de vários países da União Europeia sobre o que designaram de «Universidade europeia», registado no tratado de Bolonha, em junho de 1999, nessa cidade italiana. ${ }^{7}$ Atualmente são 47 os países que aderiram a esta convenção que tem como objetivos permitir que o estudante realize a sua formação académica e que esta seja reconhecida no espaço europeu: com este sistema pretendeu-se aumentar a competitividade no sistema universitário europeu, bem como as possibilidades de empregabilidade neste mesmo espaço. Este tratado pretendeu criar uma base de formação superior idêntica em todos os países, sem atropelar as particularidades de cada nação, através de uma estrutura de cursos composta em ciclos, assente na de obtenção de créditos que possibilite a transferibilidade entre instituições. A mobilidade dos agentes é outro dos objetivos deste processo, com o objetivo de aumentar o conhecimento mútuo dos vários países, para uma melhor Europa (Declaração de Bolonha). ${ }^{8}$ Apesar destas preocupações procurarem garantir uma melhor qualidade na formação superior, a conjuntura vivida nesta década de operacionalização deste tratado veio condicionar o entendimento dos práticos acerca da sua validade país real, entendido como o campo pedagógico e de dinâmicas institucionais em contraponto com o discurso político. ${ }^{7}$

${ }^{2}$ Decreto-Lei no 43/2007 de 22 de Fevereiro, que especifica as condições de obtenção de habilitação profissional para a docência nos diversos domínios. ${ }^{6}$

Conexões: revista da Faculdade de Educação Física da UNICAMP, Campinas, v. 13, n. 1, p. 20-35, jan./mar. 2015. ISSN: $1983-9030$
} 
Física. Este segundo momento de estudos universitários é de natureza bianual, composto de um primeiro ano com unidades curriculares nas áreas das ciências da educação e didáticas específicas, e um segundo por uma unidade curricular estruturante, o Estágio Profissional. Esta unidade curricular é composta por duas componentes, a Prática de Ensino Supervisionada e o Relatório Final do Estágio Profissional (objeto de defesa em provas públicas), ambos com o mesmo peso na classificação final.

Neste panorama de mudança, resultante das alterações legislativas e do processo de Bolonha, a organização da unidade curricular de estágio profissional sofreu alterações substanciais em algumas instituições universitárias, designadamente a não obrigatoriedade do estudante-estagiário lecionar a disciplina de Educação Física a uma turma durante todo o ano letivo.

Concomitantemente, a este novo enquadramento formativo, a profissão atravessa uma fase marcada pela intensificação da burocratização, pelo aumento das tarefas administrativas e uma maior responsabilização e controlo público. ${ }^{9}$ Consequentemente, o tempo que o professor tem para se dedicar ao elemento central da sua atividade de professor, a preparação da componente letiva, é cada vez mais escasso. Assim, não só o modo como a escola é vivida se alterou, como emerge uma identidade profissional (IP) com novos contornos, pois a IP é histórica, relacional e situacional ${ }^{10}$. Face a esta nova realidade profissional, exige-se que os programas de formação sejam capazes de preparar os futuros professores para ela.

Neste contexto de dupla mudança, examinar as perceções de estudantes-estagiários de Educação Física sobre os programas de formação de professores em Portugal, no que concerne a vários aspetos do ensino, a componentes dos seus planos curriculares, e à contribuição desta formação para as suas vidas profissionais, ganha pertinência investigativa. Face à exiguidade de instrumentos para captar a perceção dos Estudantes Estagiários, e no cumprimento desta necessidade, o presente estudo representa o primeiro passo do processo de validação do questionário desenvolvido originalmente por Gilat, Kupferberg e Sagee ${ }^{11}$ e adaptado por Ezer, Gilat e Sagee ${ }^{12}$ - Perceção do Estudante-Estagiário sobre a Formação e a Profissão, para a realidade portuguesa. Da 
atualidade e pertinência do tema eclodiu a convicção de que, uma versão em língua Portuguesa poderia ser um contributo para formular um conhecimento renovado nos países lusófonos. A realização da tradução, tendo em vista a versão preliminar, é o primeiro passo para este propósito. Já como objetivos específicos pretendeu-se (i) traduzir o instrumento PEFP para a língua portuguesa; e (ii) adaptá-lo linguística e culturalmente à realidade portuguesa.

\section{METODOLOGIA}

\section{Instrumento}

O questionário designado por "a questionnaire for student teachers" apresentado por Ezer, Gilat e Sagee ${ }^{12}$ contempla sete partes distintas. A primeira destina-se ao registo de dados biográficos. As seis partes seguintes são compostas por três sistemas diferentes de registo da informação. Aa três primeiras reportam-se aos agentes da formação, às componentes da formação de professores e às dimensões da formação de professores, sendo cada uma delas constituídas por sete itens em que o respondente define um ranking de acordo com a importância que atribui a cada um deles. Nas duas partes seguintes é usada uma escala de Likert ${ }^{13}$ com 5 pontos, permitindo aceder a informação relativa às motivações para o ensino e às conceções acerca do ensino-aprendizagem. $\mathrm{Na}$ última parte do questionário o respondente é convidado a responder a uma questão aberta acerca da mudança mais significativa que tenha ocorrido durante o ano de estágio.

\section{Procedimentos}

No processo de tradução e adaptação linguística e cultural do instrumento acima apresentado, procedeu-se à avaliação das equivalências linguísticas, concetuais e funcionais, no sentido de transcender uma tradução literal ${ }^{14,15,16,17}$.Vallerand ${ }^{18}$ propõe o cumprimento de sete etapas no processo de tradução e adaptação transcultural: (i) construção de uma versão preliminar; (ii) avaliação e modificação da versão preliminar; (iii) avaliação da clareza das perguntas por membros da população através de um préteste; (iv) avaliação da validade e do conteúdo do questionário; (v) avaliação da fidelidade através de teste-reteste e da consistência interna do instrumento; (vi) estudo da validade do constructo do questionário e (vii) estabelecimento de normas. Neste 
estudo, tendo em conta o seu propósito, foram cumpridas as primeiras quatro etapas. As restantes serão objeto de desenvolvimento num estudo posterior.

Para o efeito, foi realizado um conjunto de procedimentos técnicos estruturado em diferentes fases: na primeira fase, foi solicitada uma autorização para a realização da tradução e adaptação cultural do questionário PEFP aos autores do instrumento. ${ }^{12}$ Obtida uma resposta positiva, passou-se à tradução do instrumento para português, a qual foi realizada por dois tradutores independentes. Posteriormente foi efetuada uma análise comparativa das duas traduções tendo-se chegado à versão preliminar do questionário em português. Nesta etapa aplicaram-se os procedimentos técnicos que permitem ultrapassar as diferenças estruturais e metalinguísticas, nomeadamente a equivalência, a naturalização, a tradução literal, a modulação, a expansão e a redução. ${ }^{16}$ A versão traduzida preliminar foi, numa terceira fase, sujeita a uma análise por um painel de peritos, constituído por dois doutorados em ciências do Desporto da área da pedagogia do desporto. Estes peritos procederam a uma verificação da terminologia específica e do rigor da tradução. Da versão que reunia maior consenso resultou a primeira versão em português do questionário. Após esta etapa, um tradutor independente fez a sua retroversão para a língua inglesa. A retroversão resultante foi analisada e enviada para os autores, no sentido de verificar a equivalência linguística e de conteúdo. Seguidamente foi efetuada a revisão da correção linguística da primeira versão do questionário por um profissional com vasta experiência na área da pedagogia do desporto e, mais concretamente, na formação de professores de Educação Física. Em resultado, deste processo, e com o acordo de todos os elementos envolvidos, chegou-se à versão final do questionário PEFP, em língua portuguesa.

\section{APRESENTAÇÃO E DISCUSSÃO DOS RESULTADOS}

Este estudo, não obstante se ter atendido aos pressupostos metodológicos dos processos de tradução de questionários defendidos por Vallerand ${ }^{18}$ e de McIntyre et al., ${ }^{19}$ a propósito da validação transcultural de questionários, resulta de um conjunto de procedimentos metodológicos, onde também se procurou incorporar a noção veiculada

por Maia, Almeida e Fontoura, ${ }^{20}$ que referem que a tradução literal de um instrumento não implica a sua total inteligibilidade no contexto para o qual foi traduzido. Neste 
sentido, o processo de validação foi sendo efetuado no cumprimento deste entendimento, como se poderá constatar ao longo da apresentação destes resultados.

O nome do instrumento «A questionnaire for student teachers» foi traduzido para «perceção do estudante sobre a formação e a profissão - PEFP», porquanto a tradução literal tornava-o pouco específico da informação a que pretende aceder. A abreviatura «PEFP» resulta da junção de cada inicial das palavras que compõe o nome. Esta opção contou com o consenso de toda a equipa de investigação. O nome original, embora não constando no artigo publicado, ${ }^{12}$ está definido no questionário gentilmente enviado pelas autoras.

No que diz respeito à parte $\mathrm{A}$ do questionário «Dados Pessoais», as duas traduções iniciais evidenciaram algumas diferenças na atribuição de significado, pelo que a decisão foi substituir o campo «year of study» por duas questões - «instituição de formação inicial $\left(1^{\circ}\right.$ ciclo $)$ » e «instituição de formação inicial $\left(2^{\circ}\right.$ ciclo $)$ ». Esta alteração justifica-se pela necessidade de adaptar a questão à estruturação da formação académica em Portugal, que se alterou em resultado do processo de Bolonha, que contemplas a formação inicial de professores em dois ciclos de ensino ( $1^{\circ}$ e $2^{\circ}$ Ciclos $)$.

Foi também alterada a expressão «year of birth» para «idade». Considerou-se não ser relevante saber o ano de nascimento, porquanto esse dado implicaria ter que calcular a a idade de cada um dos participantes. Assim, a opção foi colocar a pergunta idade (em anos) no momento do preenchimento do questionário, tornando a informação mais funcional.

$\mathrm{O}$ item «fyeld of specialization» foi substituído pela questão «experiência profissional prévia ao estágio»e, em caso de resposta afirmativa, «se sim, em que área»e «quanto tempo (em anos)». A decisão de questionar acerca das experiências prévias ao estágio, em substituição do ano do curso que frequentam justifica-se pela população que se pretende aceder, isto é, estudantes-estagiários que frequentam o $2^{\circ}$ ano do $2^{\circ}$ ciclo de estudos em ensino. Acresce que aceder a informações relativas às experiências prévias ao estágio pode contribuir para explicação de alguns resultados, bem como para 
caraterizar melhor o perfil dos estudantes. Considerou-se ainda pertinente saber qual a duração, em anos, dessa mesma experiência profissional.

$\mathrm{Na}$ parte $\mathrm{B}$ do questionário, relativa à valorização dos diferentes agentes da formação, foram identificadas quatro alterações na primeira tradução face ao original, como mostra o Quadro 1. Todas elas foram justificadas pela necessidade de adaptação linguística e cultural à realidade educativa portuguesa com o objetivo de agrupar os professores das diferentes áreas de formação em função da estrutura dos currículos nacionais da formação de professores. Assim, as grandes diferenças entre a versão original e a retroversão (ambas em língua Inglesa) encontram explicação nas adaptações culturais. As quatro alterações foram: i) agrupamento dos «professores das áreas das ciências da educação» em alternativa aos «professores de unidades curriculares de formação educacional geral»; ii) especificação dos «professores das componentes de ciências do desporto e do movimento humano» (este foi ajustado face à pluralidade de conceções de formação de professores em Portugal), o qual correspondente à expressão original «subject matters lectures (literature, science, mathematics, etc)». A necessidade adveio do facto da expressão original incorporar docentes de áreas que não integram os planos curriculares vigentes; iii) inclusão dos «professores das componentes de didáticas específicas». Esta decisão foi consensual, porquanto os professores que abordam o ensino de cada modalidade são em número considerável. Este agente veio substituir os «core subjetc lecturers (ESL, Hebrew language, Bible, etc.)» dado que no quadro de formação de professores em Portugal, este tipo de agentes e unidades curriculares é inexistente; por último iv) substituição do agente «professores do mesmo grupo disciplinar» como tradução de «Subject matter instructors» por «outros agentes». Desta forma, contemplou-se nesta expressão todos os agentes que, por não estarem circunscritos nas outras expressões, possam ter contribuído para a formação do estudante-estagiário. Foi ainda alterada a expressão «unidades curriculares» para «componentes», porquanto o termo inicial restringia a influência a um agente, isto é, ao professor de determinada unidade curricular, e o termo componentes alargou o âmbito de influência aos professores que atuam numa determinada área. 
Quadro 1 - Diferenças entre as traduções na parte B (agentes da formação) do questionário

\begin{tabular}{|c|c|c|c|}
\hline Original & $1^{\mathrm{a}}$ Tradução & Retroversão & Versão Final \\
\hline $\begin{array}{ll}\text { Subject } & \text { matter } \\
\text { instructors } & \end{array}$ & $\begin{array}{l}\text { Professores do mesmo Grupo } \\
\text { Disciplinar }\end{array}$ & $\begin{array}{l}\text { Other Teachers from the } \\
\text { same curriculum area }\end{array}$ & Outros agentes \\
\hline $\begin{array}{l}\text { Lecturers of } \\
\text { educational subjects } \\
\text { (sociology, } \\
\text { psychology, etc.) }\end{array}$ & $\begin{array}{lrr}\text { Professores } & \text { de } & \text { Unidades } \\
\text { Curriculares } & \text { de } & \text { Formação } \\
\text { Educacional } & \text { Geral } \\
\text { (Sociologia, } & \text { Psicologia, } \\
\text { Investigação } & \text { Educativa, } \\
\text { Desenvolvimento } & \text { Curricular, } \\
\text { Gestão Escolar, ...) }\end{array}$ & 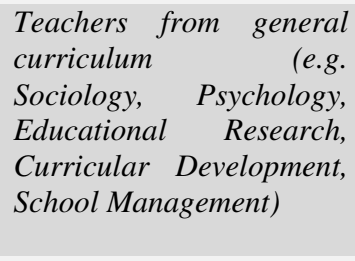 & 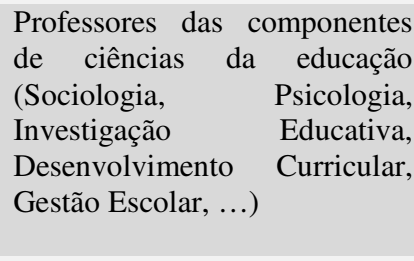 \\
\hline $\begin{array}{l}\text { Subject matter } \\
\text { lecturers (literature, } \\
\text { science, } \\
\text { mathematics, etc.) }\end{array}$ & 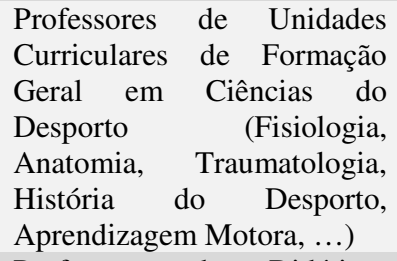 & $\begin{array}{l}\text { Teachers in curriculum } \\
\text { areas belonging to Sports } \\
\text { Sciences (Physiology, } \\
\text { Anatomy, Traumatology, } \\
\text { Sports History, Motor } \\
\text { Learning) }\end{array}$ & $\begin{array}{lr}\text { Professores das } & \text { componentes } \\
\text { de ciências do desporto ou do } \\
\text { movimento } & \text { humano } \\
\text { (Sociologia, } & \text { Psicologia, } \\
\text { Investigação } & \text { Educativa, } \\
\text { Desenvolvimento } & \text { Curricular, } \\
\text { Gestão Escolar, ...) } & \end{array}$ \\
\hline $\begin{array}{lr}\text { Core } & \text { subject } \\
\text { lecturers } & \text { (ESL, } \\
\text { Hebrew language, } \\
\text { Bible, etc.) }\end{array}$ & $\begin{array}{l}\text { Professores das Didáticas } \\
\text { Específicas }\end{array}$ & $\begin{array}{l}\text { Teachers from sport } \\
\text { specific didactics }\end{array}$ & $\begin{array}{l}\text { Professores das componentes } \\
\text { de didáticas específicas }\end{array}$ \\
\hline
\end{tabular}

Na parte $\mathrm{C}$ do questionário, conforme Quadro 2, todas as dimensões consideradas no instrumento original foram mantidas (tradução literal), contudo o termo «studies», traduzido inicialmente por «trabalhos», foi substituído por «formação» na expressão «disciplinary/subject matter studies», em que se optou por especificar a área onde a formação foi realizada. Assim na tradução ficou: «formação em ciências do desporto ou movimento humano (Biomecânica, Fisiologia do esforço, aprendizagem motora ...)». Assim, procurou contemplar-se o reconhecimento mais efetivo das diferentes áreas que podem ter contribuído para a formação dos estudantes-estagiários. Outras adaptações culturais passaram pela substituição do termo «computer studies», pela expressão de uso comum nos currículos portugueses «tecnologias de informação e computação (TIC)», assim como «mentoring school» por «escola cooperante».

Da primeira versão traduzida para a versão final, e após análise dos dois peritos, as expressões «assistência às aulas (conhecimento teórico)» e «trabalhos em núcleo de estágio» foram alteradas para expressões que retomaram a tradução literal do original, respetivamente «literacia académica (formação académica geral, recursos intelectuais)» e «aprender a trabalhar em equipa na escola cooperante». 
Relativamente à expressão «Didactic classes (e.g., didactics, curriculum planning, teaching basic concepts)», pese embora tenha sido traduzida como «aulas das didáticas específicas», decidiu-se uniformizar a terminologia desta parte do questionário, pelo que se acrescentaram as áreas de configuração pedagógica da ação do professor “planeamento, realização e avaliação do ensino".

Quadro 2 - Diferenças entre as traduções na parte C (dimensões da formação) do questionário

\begin{tabular}{|c|c|c|c|}
\hline Original & $1^{\text {a }}$ Tradução & Retroversão & Versão Final \\
\hline Education & Trabalhos & Assignments & Formação \\
\hline $\begin{array}{l}\text { Disciplinary/ } \\
\text { subject matter } \\
\text { studies }\end{array}$ & $\begin{array}{l}\text { Trabalhos sobre } \\
\text { curriculares das } \\
\begin{array}{l}\text { outras áreas } \\
\text { Ciências do } \\
\text { (Biomecânica, }\end{array} \\
\text { Fisiologia, ...) }\end{array}$ & $\begin{array}{l}\text { Assignments on other } \\
\text { curriculum areas within } \\
\text { Sports } \\
\text { (Biomechanics, } \\
\text { Physiology, ...) }\end{array}$ & $\begin{array}{l}\text { Formação em ciências do } \\
\text { desporto ou movimento } \\
\text { humano } \\
\text { Fisiologia do esforço, } \\
\text { aprendizagem motora ...) }\end{array}$ \\
\hline $\begin{array}{l}\text { Computer } \\
\text { studies }\end{array}$ & $\begin{array}{l}\text { Trabalhos sobre tecnologias da } \\
\text { informação e computação (TIC) }\end{array}$ & $\begin{array}{l}\text { Assignments requiring } \\
\text { informatics skills }\end{array}$ & $\begin{array}{l}\text { Formação em tecnologias } \\
\text { da informação } \\
\text { computação (TIC) }\end{array}$ \\
\hline $\begin{array}{l}\text { Academic } \\
\text { literacy }\end{array}$ & $\begin{array}{l}\text { Assistência às aulas } \\
\text { (conhecimento teórico) }\end{array}$ & $\begin{array}{l}\text { Class Attendance } \\
\text { (theoretical } \\
\text { understanding) }\end{array}$ & $\begin{array}{l}\text { Literacia académica } \\
\text { (formação académica geral, } \\
\text { recursos intelectuais) }\end{array}$ \\
\hline $\begin{array}{l}\text { Team learning } \\
\text { in the } \\
\text { mentoring } \\
\text { school }\end{array}$ & Trabalhos em núcleo de estágio & $\begin{array}{l}\text { Assignments during } \\
\text { practicum training }\end{array}$ & $\begin{array}{l}\text { Aprender a trabalhar em } \\
\text { equipa na escola cooperante }\end{array}$ \\
\hline $\begin{array}{l}\text { Didactic } \\
\text { classes (e.g., } \\
\text { didactics, } \\
\text { curriculum } \\
\text { planning, } \\
\text { teaching basic } \\
\text { concepts) }\end{array}$ & Aulas das didáticas específicas & $\begin{array}{l}\text { Sport Specific Didactic } \\
\text { Classes }\end{array}$ & $\begin{array}{l}\text { Aulas de } \begin{array}{r}\text { didáticas } \\
\text { específicas (planeamento, } \\
\text { realização e avaliação do } \\
\text { ensino) }\end{array}\end{array}$ \\
\hline
\end{tabular}

Na parte $\mathrm{D}$, dirigida aos papéis dos professores, destaca-se a não alteração da tradução literal da primeira versão para a segunda, no caso da expressão «Educating for appropriate behavior and prevention of violence» $\mathrm{e}$ «Imparting patriotic and patriotic values» e o retorno, no segundo round, à tradução literal da expressão «Imparting patriotic and patriotic values» (QUADRO 3).

Conexões: revista da Faculdade de Educação Física da UNICAMP, Campinas, v. 13, n. 1, p. 20-35, jan./mar. 2015. ISSN: 1983-9030 
Quadro 3 - Diferenças entre as traduções na parte D (papéis dos professores) do questionário

\begin{tabular}{|c|c|c|c|}
\hline Original & $1^{\text {a }}$ Tradução & Retroversão & Versão Final \\
\hline $\begin{array}{l}\text { Educating for } \\
\text { appropriate } \\
\text { behavior and } \\
\text { prevention of } \\
\text { violence }\end{array}$ & $\begin{array}{l}\text { Educar para } \\
\text { comportamentos } \\
\text { socialmente aceites e } \\
\text { para a prevenção da } \\
\text { violência }\end{array}$ & $\begin{array}{l}\text { To teach socially } \\
\text { acceptable behaviour } \\
\text { and to prevent violence }\end{array}$ & $\begin{array}{l}\text { Educar para } \\
\text { comportamentos } \\
\text { apropriados e para a } \\
\text { prevenção da violência }\end{array}$ \\
\hline $\begin{array}{l}\text { Imparting } \\
\text { patriotic and } \\
\text { patriotic values }\end{array}$ & $\begin{array}{l}\text { Transmitir valores de } \\
\text { cidadania }\end{array}$ & $\begin{array}{l}\text { To transmit citizenship } \\
\text { values }\end{array}$ & $\begin{array}{l}\text { Transmitir } \\
\text { patrióticos }\end{array}$ \\
\hline
\end{tabular}

Na parte E - motivação para o ensino - não obstante na primeira tradução não ter sido efetuada uma tradução literal de algumas expressões, na segunda versão, após a retroversão, a opção foi pela tradução literal (QUADRO 4). Menciona-se, a título ilustrativo, a expressão «I regard myself as a successful teacher», que inicialmente foi traduzida por «considero que sou um professor bem-sucedido», e na versão final optouse por manter a tradução literal, designadamente no que concerne à manutenção do verbo. $\mathrm{O}$ mesmo aconteceu nas restantes expressões.

Quadro 4 - Diferenças entre as traduções na parte E (motivações para o ensino) do questionário

\begin{tabular}{|c|c|c|c|}
\hline Original & $\mathbf{1}^{\text {a }}$ Tradução & Retroversão & Versão Final \\
\hline $\begin{array}{l}\text { I regard myself as a } \\
\text { successful teacher }\end{array}$ & $\begin{array}{l}\text { Considero que sou um } \\
\text { professor bem-sucedido. }\end{array}$ & $\begin{array}{l}\text { I believe I am a } \\
\text { successful teacher. }\end{array}$ & $\begin{array}{l}\text { Vejo-me como um } \\
\text { professor bem-sucedido }\end{array}$ \\
\hline $\begin{array}{l}\text { I see myself engaging } \\
\text { in teaching in the near } \\
\text { future }\end{array}$ & $\begin{array}{l}\text { Vejo-me a dar aulas num } \\
\text { futuro próximo. }\end{array}$ & $\begin{array}{l}\text { I see myself } \\
\text { teaching in the near } \\
\text { future. }\end{array}$ & \begin{tabular}{llr} 
Vejo-me & \multicolumn{2}{c}{ ligado ao } \\
ensino & num futuro \\
próximo & &
\end{tabular} \\
\hline $\begin{array}{l}\text { Teaching promotes } \\
\text { self-realization }\end{array}$ & $\begin{array}{l}\mathrm{O} \text { ensino promove a } \\
\text { autorrealização. }\end{array}$ & $\begin{array}{l}\text { I fulfil myself } \\
\text { through teaching. }\end{array}$ & $\begin{array}{l}\text { Ensinar promove } \\
\text { autorrealização }\end{array}$ \\
\hline $\begin{array}{lr}\text { The } & \text { teaching } \\
\text { profession } & \text { offers } \\
\text { convenient } & \text { work } \\
\text { conditions } & \end{array}$ & $\begin{array}{l}\text { A profissão de professor } \\
\text { ocorre com condições } \\
\text { adequadas de trabalho. }\end{array}$ & $\begin{array}{l}\text { I have adequate } \\
\text { working conditions } \\
\text { to teach. }\end{array}$ & $\begin{array}{l}\text { A profissão docente } \\
\text { oferece boas condições } \\
\text { de trabalho }\end{array}$ \\
\hline $\begin{array}{l}\text { The teaching } \\
\text { profession enables a } \\
\text { relationship } \\
\text { children with } \\
\text { established }\end{array}$ & $\begin{array}{l}\text { A profissão de professor } \\
\text { permite que se estabeleça } \\
\text { uma interação com os } \\
\text { alunos. }\end{array}$ & $\begin{array}{l}\text { I can establish an } \\
\text { interaction with } \\
\text { students as a } \\
\text { teacher. }\end{array}$ & $\begin{array}{l}\text { A profissão docente } \\
\text { permite que se estabeleça } \\
\text { uma relação com os } \\
\text { alunos }\end{array}$ \\
\hline
\end{tabular}

Relativamente à parte $\mathrm{F}$ - conceções de ensino e aprendizagem - a lógica de tradução anteriormente apresentada (tradução literal) foi mantida. Conforme está patente no Conexões: revista da Faculdade de Educação Física da UNICAMP, Campinas, v. 13, n. 1, p. 20-35, jan./mar. 2015. ISSN: 1983-9030 
Quadro 5, a versão final das expressões assenta na tradução literal, respeitando o critério de começar com o verbo sempre que a expressão original assim o definia.

Quadro 5- Diferenças entre as traduções no grupo F (conceções de ensinoaprendizagem) do questionário

\begin{tabular}{|c|c|c|c|}
\hline Original & $1^{\mathrm{a}}$ Tradução & Retroversão & Versão Final \\
\hline $\begin{array}{l}\text { I like to organize my } \\
\text { learning processes } \\
\text { by myself }\end{array}$ & $\begin{array}{l}\text { Gosto de ser eu a organizar } \\
\text { o meu processo de ensino- } \\
\text { aprendizagem. }\end{array}$ & $\begin{array}{l}\text { I like to organise my own } \\
\text { process of teaching and } \\
\text { learning }\end{array}$ & $\begin{array}{l}\text { Gosto de ser eu a organizar } \\
\text { os meus processos de } \\
\text { aprendizagem }\end{array}$ \\
\hline $\begin{array}{l}\text { Generally speaking, } \\
\text { I rate my ability to } \\
\text { function as a } \\
\text { teacher as a high } \\
\text { ability nowadays }\end{array}$ & $\begin{array}{l}\text { Em geral, avalio a minha } \\
\text { função como /de professor } \\
\text { como uma atividade de } \\
\text { elevada competência. }\end{array}$ & $\begin{array}{l}\text { In general I look at my } \\
\text { work as a teacher as a } \\
\text { highly specialised job. }\end{array}$ & $\begin{array}{l}\text { Em geral, no momento } \\
\text { atual, avalio a minha } \\
\text { capacidade para ser } \\
\text { professor num nível de } \\
\text { elevada competência }\end{array}$ \\
\hline $\begin{array}{l}\text { I like to be given } \\
\text { clear frameworks } \\
\text { and } \quad \text { defined } \\
\text { objectives } \\
\text { learning in }\end{array}$ & $\begin{array}{l}\text { Quando estou a aprender } \\
\text { gosto que me sejam } \\
\text { fornecidos enquadramentos } \\
\text { claros e objetivos bem } \\
\text { definidos. }\end{array}$ & $\begin{array}{l}\text { When I am learning, I like } \\
\text { to be given a clear context } \\
\text { as well as clear learning } \\
\text { objectives. }\end{array}$ & $\begin{array}{l}\text { Gosto que me forneçam } \\
\text { quadros concetuais claros e } \\
\text { objetivos bem definidos na } \\
\text { aprendizagem }\end{array}$ \\
\hline $\begin{array}{l}\text { I manage to find } \\
\text { bibliographical } \\
\text { sources on my own }\end{array}$ & $\begin{array}{l}\text { Tenho autonomia para } \\
\text { encontrar as fontes } \\
\text { bibliográficas. }\end{array}$ & $\begin{array}{l}\text { I can find bibliographic } \\
\text { sources on my own. }\end{array}$ & $\begin{array}{l}\text { Sou capaz de procura fontes } \\
\text { bibliográficas } \\
\text { autonomamente }\end{array}$ \\
\hline $\begin{array}{l}\text { I manage to } \\
\text { establish a link } \\
\text { between theoretical } \\
\text { knowledge and } \\
\text { practical experience } \\
\text { at work }\end{array}$ & $\begin{array}{l}\begin{array}{l}\text { No exercício da função de } \\
\text { professor }\end{array} \\
\text { estabelecer } \\
\text { estama } \\
\text { entre o relação } \\
\text { teórico e a conhecimento } \\
\text { prática. }\end{array}$ & $\begin{array}{l}\text { As a teacher, I can establish } \\
\text { a relationship between } \\
\text { theory and practical } \\
\text { experience. }\end{array}$ & $\begin{array}{l}\text { Consigo estabelecer uma } \\
\text { relação entre } \\
\text { conhecimento teórico e a } \\
\text { experiência prática, no meu } \\
\text { ensino }\end{array}$ \\
\hline
\end{tabular}

A última parte do questionário, pergunta de resposta aberta - «Describe 'the most significant change that you experienced in the course of your teacher education'» foi traduzida, na primeira versão, por "descreva a mudança mais significativa que experienciou no decurso da sua formação inicial ( $1^{\circ}$ e $2^{\circ}$ ciclo) para professor". Esta tradução foi mantida na versão final e respeita uma correspondência literal ao original, com exceção do nome atribuído ao curso de formação para professor. Concretamente, termina com a expressão «... formação inicial $\left(1^{\circ}\right.$ e $2^{\circ}$ ciclo $) \ldots$... como tradução «... teacher education...», por se ajustar à realidade da formação de professores em Portugal, isto é, com base na atual composição curricular dos cursos superiores (processo de Bolonha).

\section{CONSIDERAÇÕES FINAIS}

O processo de tradução e adaptação do questionário, agora denominado de «perceção do estudante sobre a formação e a profissão - PEFP» foi alcançado. Assim, foi exequível 
construir um instrumento passível de ser submetido às restantes etapas de validação, designadamente ao estudo da fiabilidade e validade. O próximo passo a efetuar de validação do instrumento deverá ser a análise das propriedades psicométricas, dando assim cumprimento à metodologia sugerida por Vallerand, ${ }^{18}$ que permitirá conferir legitimidade ao instrumento no seio da comunidade científica.

O término deste processo de tradução e validação do questionário permitirá obter um instrumento consistente que permita aceder às opiniões dos atores da formação, neste caso dos estudantes-estagiários, sendo que se traduzirá num importante contributo para a melhoria do (re)novado processo de formação de professores que recentemente teve início. Deste modo, ao acedermos aos seus entendimentos e perceções, espera-se aceder a uma melhor compreensão dos processos formativos de modo a que seja possível renová-los e melhorá-los.

\section{REFERÊNCIAS}

${ }^{1}$ LIMA, J. Redes na educação: questões políticas e conceptuais. Revista Portuguesa de Educação, Braga, v. 20, n. 2, p. 151-181, jun. 2007.

${ }^{2}$ DYMOKE, S.; HARRISON, J. K. Professional development and the beginning teacher: issues of teacher autonomy and institutional conformity in the performance review Process. Journal of Education for Teaching: international research and pedagogy, London, v. 32, n. 1, p. 71-92, feb. 2006.

${ }^{3}$ MEIJER, P.; DE GRAAF, G.; MEIRINK, J. Key experiences in student teachers' development. Teachers and Teaching: theory and practice, London, v.17, n. 1, p. 115-129, dez. 2011.

${ }^{4}$ DOTGER, B.; SMITH, M. "Where's the line?"-negotiating simulated experiences to define teacher identity. New Educator, London, v. 5, n. 2, p. 161-180, july 2009.

${ }^{5}$ SUTHERLAND, L.; HOWARD, S.; MARKAUSKAITE, L. Professional identity creation: Examining the development of beginning preservice teachers' understanding of 
their work as teachers. Teaching and Teacher Education, v. 26, n. 3, p. 455-465, june 2010.

${ }^{6}$ PORTUGAL. Decreto-Lei n ${ }^{\text {4 }}$ 43/2007 de 22 de Fevereiro. Aprova o regime jurídico da habilitação profissional para a docência na educação pré-escolar e nos ensinos básico e secundário. Diário da República Portuguesa, Lisboa, 1a série, n. 38, p. 1320-1328, 22 fev. 2007.

${ }^{7}$ VEIGA, A.; AMARAL, A. Uma interpretação do olhar da história sobre Bolonha. História: revista da FLUP, Porto, v. 1, p. 29-40, 2011.

${ }^{8}$ DECLARAÇÃO DE BOLOnHA. The Bologna Declaration of 19 June 1999. Bolonha, jun. $1999 . \quad$ Disponível em http://www.ehea.info/Uploads/Declarations/BOLOGNA_DECLARATION1.pdf. Acesso em: 11 dez. 2013.

${ }^{9}$ DAY, C.; FLORES, M.; VIANA, I. Effects of national policies on teachers' sense of professionalism: findings from an empirical study in Portugal and in England. European Journal of Teacher Education, London, v. 30, n. 3, p. 249-265, ago. 2007

${ }^{10}$ CAZALES, Z. Construcción de una identidad profesional. los pedagogos de la Universidad Nacional Autónoma de México y de la Universidad Veracruzana. Revista Mexicana de Investigación Educativa, Ciudad de Mexico, v. 13, n. 36, p. 143-171, mar. 2008.

${ }^{11}$ GILAT, I.; KUPFERBERG, I.; SAGEE, R. Cholelut azmit utfisot mikzoa ha'oraah bekerev studentiyot lehoraah: Nekudot mabat kamutit ve'eichutit [Self-efficacy and perception of the teaching profession of student teachers in training: A quantitative and qualitative perspective]. Mahalakhim Lehinukh: lehevra uletarbut, Israel, v. 35, n. 8. 2006.

Conexões: revista da Faculdade de Educação Física da UNICAMP, Campinas, v. 13, n. 1, p. 20-35, jan./mar. 2015. ISSN: 1983-9030 
${ }^{12}$ EZER, H.; GILAT, I.; SAGEE, R. Perception of teacher education and professional identity among novice teachers. European Journal of Teacher Education, London. 33, n. 4, p. 391-404. out. 2010.

${ }^{13}$ LIKERT, R. A Technique for the measurement of attitudes. New York: Archives of Psychology, 1932.

${ }^{14}$ ALMEIDA, L.; FREIRE, T. Metodologia de investigação em psicologia e educação. Braga: Psiquilíbrios, 2000.

${ }^{15}$ GEISINGER, F. Cross-Cultural Normative Assessment: Translation and Adaption Issues Influencing the Normative Interpretation of Assessment Instruments. Psycological Assessment, Washington, v. 6, n. 4, p. 304-312, dez. 1994.

${ }^{16}$ VILELA, M.; BARROS, V. Técnicas de tradução de inglês: traduzir = comunicar. Porto: Porto Editora. 2000.

${ }^{17}$ HILL, M.; HILL, A. Investigação por questionário. 2. ed. Lisboa: Sílabo, 2005.

${ }^{18}$ VALLERAND, R. Vers une méthodologie de validation transculturelle de questionnaires psychologies: implications pour la recherche en langue française. Canadian Psychology/Psychologie Canadienne, Montréal v. 30, n. 4, p. 662-680, out.1989.

${ }^{19}$ MCINTYRE, T. et al. The generalizability of aggressiveness and assertiveness factors: A cross-cultural analysis. Personality and Individual Differences, Oxford, v. 10, n. 4, p. 385-389, abr. 1989.

${ }^{20}$ MAIA, J.; ALMEIDA, P.; FONTOURA, J. Adaptação portuguesa da Escala de AutoConceito Físico (PSDQ): um estudo de análise factorial confirmatória. In: ALMEIDA, L. et al. Avaliação psicológica: formas e contextos. Braga: APPORT, 1996. p. 443-449. v. 4.

Conexões: revista da Faculdade de Educação Física da UNICAMP, Campinas, v. 13, n. 1, p. 20-35, jan./mar. 2015. ISSN: 1983-9030 


\section{Agradecimentos}

Este trabalho é parte integrante do projeto financiado pela Universidade do Porto, através dos Projetos IJUP 2011 com a referência PP_IJUP2011 69.

Recebido em: 13 mar. 2014

Aceito em: 19 mar. 2015 Contato: tsousa@fade.up.pt 